\title{
Historia Bizancjum w programie VI Kongresu Mediewistów Polskich (Wrocław, 20-22 września 2018) ${ }^{1}$
}

Kongresy mediewistyczne są organizowane regularnie od roku 2002. Pierwszy odbył się w Toruniu (16-18 IX 2002), następne zaś miały miejsce kolejno w Lublinie (18-21 IX 2005), w Lodzi (22-24 IX 2008), w Poznaniu (19-21 IX 2011) i w Rzeszowie (20-24 IX 2015). Szósty kongres mediewistyczny, który tym razem odbył się we Wrocławiu, skupił bardzo liczne grono badaczy średniowiecza. W kongresie wzięło bowiem czynny udział 188 osób, które reprezentowały 63 krajowe i zagraniczne placówki naukowo-badawcze.

Z tych ostatnich przybyło do Wrocławia piętnastu badaczy, którzy pochodzili z tyluż zagranicznych instytucji naukowych, którymi były (1) Centrum Medievistikých Studíi. Akademie Věd České Republiky (Praga/Czechy) - dr Martin Nodl; (2) Eötvös Loránd Tudományegyetem = Uniwersytet im. Loránda Eötvösa (Budapeszt/Węgry) - dr László Tapolcai; (3) Институт Истории Материальной Культуры Российской Академии Наук (Sankt-Petersburg/Rosja) - dr hab. Александр Е. Мусин; (4) Johannes Gutenberg-Universität (Moguncja/Niemcy) - mgr Jakub Sypiański; (5) Київський Үніверситет імені Бориса Грінченка (Kijów/Ukraina) - dr Віталій Міхаловський; (6) Львівський Національний Үніверситет імені Івана Франка (Lwów/Ukraina) mgr Назар Різун; (7) Національна Академія Наук Украӥни (Kijów/ Ukraina) - prof. dr hab. Алексей Толочко; (8) Ostravská Univerzita (Ostrawa/Czechy) - dr Robert Antonin; (9) Pécsi Tudományegyetem = Uniwersytet w Peczu (Pecz/Wegry) - prof. dr hab. Dániel Bagi; (10) Прикарпатський Національний Үніверситет імені Василя Стефаника (Iwano-Frankowsk/Ukraina) - dr Мирослав М. Волощук; (11) Русский Государственный Гуманитарный Университет (Moskwa/Rosja) - prof. dr hab. Константин Ю. Ерусалимский; (12) Софийски Үниверситет „Св. Климент Охридски” (Sofia/Butgaria) - prof. dr hab. Цветелин Степанов; (13) Universität Leipzig: Leibniz-Institut für Geschichte und Kultur des östlichen Europa (Lipsk/Niemcy) - prof. dr hab. Christian

Niniejsze sprawozdanie napisano na podstawie dwóch informatorów kongresowych: Media aetas - historia viva. Średniowiecze-historia żywa. VI Kongres Mediewistów Polskich 2018. Abstrakty, Wrocław 2018; Media aetas - historia viva. Średniowiecze - historia żywa. VI Kongres Mediewistów Polskich, Wrocław, 20-22 września 2018. Program, Wrocław 2018. Pomocna okazała się również strona internetowa kongresu znajdująca się pod adresem http://www.vikmp.pl [dostęp: 30.09.2018]. 
Lübke; (14) Univerzita Karlova (Praga/Czechy) - mgr Magda Králová; (15) Westfälische Wilhelms-Universität (Münster/Niemcy) - prof. dr hab. Eduard Mühle.

173 naukowców natomiast legitymowało się afiliacją do 48 polskich instytucji. Do najliczniej reprezentowanych placówek należały (1) Uniwersytet Wrocławski - 26 osób; (2) Uniwersytet Łódzki - 15 osób; (3) Uniwersytet im. Adama Mickiewicza (Poznań) - 13 osób; (4) Uniwersytet Jagielloński (Kraków) - 11 osób; (5) Uniwersytet Warszawski - 11 osób; (6) Instytut Historii PAN (Warszawa) - 10 osób; (7) Instytut Archeologii i Etnologii PAN (Warszawa) - 9 osób; (8) Uniwersytet Papieski Jana Pawła II w Krakowie - 6 osób; (9) Uniwersytet Gdański - 5 osób; (10) Uniwersytet im. Marii Curie-Skłodowskiej (Lublin) - 5 osób; (11) Uniwersytet Śląski - 5 osób; (12) Uniwersytet im. Mikołaja Kopernika (Toruń) - 4 osoby; (13) Uniwersytet Rzeszowski - 4 osoby; (14) Uniwersytet Pedagogiczny im. Komisji Edukacji Narodowej (Kraków) - 3 osoby; (15) Uniwersytet Szczeciński - 3 osoby. Spośród pozostałych 33 instytucji 8 było reprezentowanych przez dwie osoby, 25 ośrodków zaś wydelegowało tylko po jednym przedstawicielu. Jak wynika z powyższego zestawienia, prawem gospodarza najliczniejszą reprezentację wystawił Uniwersytet Wrocławski. Następne zaś co do liczebności ekipy przybyły z Uniwersytetu Łódzkiego oraz z Uniwersytetu im. Adama Mickiewicza.

Najliczniej reprezentowanym środowiskiem naukowym natomiast był zespół mediewistów warszawskich, ponieważ łączna liczba badaczy afiliowanych do 8 stołecznych instytucji naukowych zamknęła się liczbą 37 osób. Drugi w tej sumarycznej statystyce był Wrocław, gdzie 4 instytucje reprezentowało łącznie 30 badaczy. Trzecie miejsce zajął Kraków, którego 5 placówek naukowo-badawczych wydelegowało w sumie na wrocławski kongres 22 osoby. Czwarta pozycja w rankingu środowiskowym przypadła Łodzi (3 instytucje i 17 osób). Czołówkę tę zamyka Poznań reprezentowany przez 3 instytucje, z których przybyło łącznie 15 prelegentów. Statystyka ta pokazuje, że z wyżej wymienionych pięciu ośrodków pochodziło aż $121(64,361 \%)$ czynnych uczestników kongresu, którzy reprezentowali 23 placówki naukowo-badawcze lub naukowo-dydaktyczne, co stanowi 36,507\% wszystkich instytucji (23/63), z których przybyli uczestnicy wrocławskiego spotkania. W skali ogólnopolskiej (23/48) natomiast daje to aż $47,916 \%$.

Jeśli zaś chodzi o strukturę ,hierarchiczną” stopni i tytułów, to przedstawia się ona następująco (tab. I): 


\begin{tabular}{|c|c|c|c|c|}
\hline \hline stopień/tytul naukowy & mgr & $\mathrm{dr}$ & $\begin{array}{c}\mathrm{dr} \text { hab. } \\
\text { (+ prof. uczeln. })\end{array}$ & prof. dr hab. \\
\hline liczba osób & 34 & 56 & 58 & 40 \\
\hline udzial procentowy & $18,085 \%$ & $29,787 \%$ & $30,851 \%$ & $21,276 \%$ \\
\hline
\end{tabular}

Tab. I: Struktura stopni i tytułów

Widać tutaj wyraźnie przewagę doświadczonych badaczy i swego rodzaju ,zanik” młodej kadry, co jest w dużym stopniu wynikiem kierun$\mathrm{ku}$ prowadzonych aktualnie reform $\mathrm{w}$ polskim szkolnictwie wyższym. Niepokoić musi szczególnie niski procentowy udział doktorantów (mgr), tym bardziej że nawet wielu spośród tych, którzy wzięli udział w kongresie, niekoniecznie musi związać swą przyszłość z pracą naukową czy też naukowo-dydaktyczną.

Jeszcze wyraźniej trend ten pokazuje tabela II. Jest to swoiste memento mori dla współczesnej polskiej historii średniowiecznej, czy szerzej nauk historycznych jako takich. Konsekwencją tej tendencji będzie w niedługim czasie duża luka pokoleniowa, połączona z brakiem mistrzów, od których młodsi koledzy mogliby uczyć się niełatwego przecież historycznego rzemiosła.

\begin{tabular}{|c|c|}
\hline doktoranci i młodsi pracownicy & pracownicy samodzielni \\
\hline $90(=47,872 \%)$ & $98(=52,127 \%)$ \\
\hline
\end{tabular}

Tab. II: Proporcje pracowników niesamodzielnych do samodzielnych

Na program VI Kongresu Mediewistów Polskich złożyły się cztery sesje plenarne, $\mathrm{z}$ których pierwsza miała miejsce w czwartek (20 września) między 10:00 a 11:00. Następna odbyła się w piątek (21 września: 11:45-14:00). Na sobotę (22 września) natomiast zaplanowano dwie sesje plenarne: południową (11:45-13:30) i popołudniową (14:30-16:00). Resztę programu wypełniły obrady w 28 sekcjach tematycznych oraz 4 spotkania warsztatowe. Dodatkowym elementem kongresu była projekcja filmu z cyklu „Tajemnice początków Polski” pod tytułem „Droga do królestwa” w reżyserii Zdzisława Cozaca połączona z dyskusją, w której brał udział twórca filmu (czwartek, 20 IX 2018, godz. 19:00-21:00).

Ze wspomnianych wyżej 28 sekcji tematycznych trzy (sekcja 5, 9 i 14) były poświęcone historii Bizancjum.

Sekcja 5 została zatytułowana „Islam i jego założyciel w kulturze europejskiego Wschodu i Zachodu w średniowieczu”. Jej organizacji pod- 
jęły się dr hab. Teresa Wolińska, prof. UŁ, i dr Zofia Brzozowska (UŁ). Miejscem obrad był Instytut Historyczny Uniwersytetu Wrocławskiego, ul. Szewska 49 (sala 13). Sekcja ta miała swe spotkanie w czwartek, 20 IX 2018, godz. 11:30-13:45 (część 1) i godz. 15:00-18:45 (część 2). W ramach części pierwszej wygłoszono 5 referatów: (1) prof. dr hab. Marek Dziekan (UŁ), „Abu Abd Allah al-Busiri (1212-1296) jako panegirysta Proroka Muhammada"; (2) ks. dr hab. Jan Żelazny, prof. UPJPII, „Mahomet jako herezjarcha w opinii autorów chrześcijańskich do czasów Jana z Damaszku”; (3) prof. dr hab. Mirosław J. Leszka (UŁ), „Zmagania arabsko-bizantyńskie za Jana Tzimiskesa i Bazylego II w świetle słowiańskich przekładów kronik Jana Zonarasa i Konstantyna Manassesa"; (4) ks. prof. dr hab. Józef Naumowicz (UKSW), ,Mahomet jako burzyciel pogańskich posągów oraz twórca islamskiego anikonizmu - narodziny toposu (do IX w.)”; (5) dr hab. Teresa Wolińska, prof. UŁ, „Wizerunek Mahometa w świetle legend o jego chrześcijańskim nauczycielu". Po przerwie obiadowej odbyła się druga część spotkania sekcji, na którą złożyło się sześć prelekcji: (1) dr Zofia Brzozowska (UŁ), „Bulwersująca podległość czy karygodna niezależność? Obraz kobiet arabskich w średniowiecznych tekstach ruskich"; (2) mgr Jakub Sypiański (Johannes Gutenberg-Universität Mainz), „Gdy wiedza pochodzi od Saracena. Niektóre ideologiczne problemy recepcji nauki pochodzenia bliskowschodniego w Konstantynopolu (VIII-XI wiek)”; (3) mgr Maciej Dawczyk (UŁ), „Interpretacja i krytyka zasad islamu w «Contra legem Saracenorum» Riccoldo da Monte Croce"; (4) dr Małgorzata Skowronek (UŁ), „W obronie ortodoksji. Głosy antyheretyckie i antymuzułmańskie w Palei - historia, typologia, tekstologia”; (5) dr Karolina Krzeszewska (UŁ), „Osobliwe konfrontacje islamu z chrześcijaństwem na przykładzie wybranych tekstów kultury ustnej Słowian Południowych”; (6) dr hab. Przemysław Turek (UJ), „Muhammad, prorok islamu $\mathrm{w}$ świetle najstarszych chrześcijańskich źródeł syryjskich, arabskich i etiopskich". W sumie w ramach obrad sekcji piątej wygłoszono 11 referatów, przy czym autorami siedmiu z nich byli pracownicy naukowi Uniwersytetu Łódzkiego.

Sekcja 9, której organizatorem był prof. dr hab. Jan ProstkoProstyński (UAM), nosiła tytuł „Demografia imperium bizantyjskiego”. Sekcja ta obradowała również w Instytucie Historycznym Uniwersytetu Wrocławskiego, ul. Szewska 49 (sala 18), w czwartek, 20 IX 2018, między godzina 15:00 a 18:45. Wyniki swych badań przedstawiło tutaj pięciu naukowców: (1) dr hab. Sławomir Bralewski, prof. UŁ, „Liczba chrześcijan w epoce przełomu konstantyńskiego"; (2) prof. dr hab. Marek Wilczyński (UP KEN), „Kilka uwag o ludności rzymskiej i ludności barbarzyńskiej w prowincjach afrykańskich pod panowaniem wandalskim"; (3) dr hab. 
Jacek Wiewiorowski, prof. UG, „Zmiany etniczne na Bałkanach w okresie wczesnobizantyjskim w świetle źródeł epigraficznych"; (4) prof. dr hab. Jan Prostko-Prostyński (UAM), „Demografia Grecji w IV-VII wieku”; (5) dr Marcin Böhm (UO), „Liber ad honorem Augusti sive de rebus Siculis» jako źródło do badań demografii Sycylii w XII wieku".

Z kolei sekcja 14, ,W cieniu starego cesarstwa: bizantyńskie Bałkany od VII do końca XII wieku" została zorganizowana z inicjatywy prof. dr. hab. Mirosława J. Leszki (UŁ), dr. Kiriła Marinowa (UŁ) oraz dr. hab. Aleksandra Paronia (Instytut Archeologii i Etnologii PAN we Wrocławiu). Miejscem tego spotkania był Instytut Archeologii i Etnologii PAN, ul. Więzienna 6 (sala im. Anny i Lecha Leciejewiczów). Sekcja 14 obradowała w piątek (21 IX 2018) w dwóch turach: część 1 godz. 9:00-11:15, część 2 godz. 15:15-19:00. Na część pierwszą złożyło się pięć wystąpień: (1) dr hab. Jarosław Dudek (UZ), „Zachodnie Bałkany (VII-XIV w.) - utracone i odzyskane dla Bizancjum"; (2) dr hab. Piotr Kochanek, prof. KUL, „Schematy Bałkanów na mapach średniowiecznych”; (3) dr hab. Zdzisław Pentek, prof. UAM, „Rzetelność czy bałamuctwo? Czyli o informacjach Aḥmāda al-Balādurīego o Cesarstwie Bizantyńskim w VIII wieku"; (4) dr hab. Ireneusz Milewski, prof. UG, „Rynek pieniężny w Cesarstwie Bizantyńskim w VI i na pocz. VII wieku"; (5) dr Kirił Marinow (UŁ), „Pokój z wysokości: obraz pokoju w utworze retorycznym sławiącym zawarcie porozumienia bizantyńsko-bułgarskiego w 927 r.”. W części drugiej natomiast przedstawiono aż osiem referatów: (1) dr hab. Jacek Bonarek (UJK, Filia w Piotrkowie Trybunalskim), „Bułgarzy jako poddani Jana I Tzimiskesa”; (2) prof. dr hab. Mirosław J. Leszka (UŁ), „Obraz cara Samuela w źródłach bizantyńskich (koniec X-XII w.)"; (3) prof. dr hab. Tsvetelin Stepanov (Софийски университет „Св. Климент Охридски”), „The History and Culture of Bulgaria in the 7th-12th Centuries: Between Two Easts and Two Wests”; (4) dr Zofia Brzozowska (UŁ), „Bizantyńska czy rodzima wizja dziejów powszechnych? Wpływ tekstów bizantyńskich na świadomość historyczną Słowian bałkańskich"; (5) dr Jan M. Wolski (UŁ), „Oblicza bizantynizacji w mediewistyce bułgarskiej”; (6) dr Szymon Wierzbiński (PolŁ), „Zdrajcy, szpiedzy i maruderzy. Polityka dowództwa bizantyńskiego w świetle wybranych traktatów wojskowych z X wieku"; (7) dr hab. Anna Kotłowska, prof. UAM, „Problematyka wołoska w Historii Jerzego Akropolity"; (8) dr hab. Aleksander Paroń (Instytut Archeologii i Etnologii PAN we Wrocławiu), „Niechciani uchodźcy - Bizancjum a ludy koczownicze na Bałkanach w XI-XII wieku (Pieczyngowie, Uzowie, Kumanowie)".

Obok sekcji poświęconych w całości zagadnieniom historii Bizancjum kilka wystąpień z tego segmentu dziejów średniowiecznych miało tak- 
że miejsce w ramach innych sekcji. I tak w czasie drugiej (popołudniowej) części spotkania sekcji 2 noszącej tytuł „Ruś wikingów i Waregów. Archeologia i historia", które odbyło się w czwartek (20 IX 2018) między godziną 15:00 a 18:45, dr Kirił Marinow (UŁ) wystąpił z wykładem noszącym tytuł „Między Dorostolonem a Presławiem. W kwestii strategii księcia Świętosława na Bałkanach w czasie wojny z Bizancjum”. Również w ramach drugiej (popołudniowej: 15:00-18:45) części obrad sekcji 3, której temat zbiorczy brzmiał „Mediewistyka historyczno-artystyczna wśród innych dyscyplin naukowych”, dr hab. Mirosław P. Kruk (prof. UG) zaprezentował swe przemyślenia opatrzone tytułem „Na skrzyżowaniu badań ikonografii średniowiecznej sztuki zachodnioeuropejskiej i cerkiewnej”. Z kolei sekcja 7 „Hortus medievalis”, której uczestnicy spotkali się tylko raz (czwartek, 20 IX 2018, godz. 11:30-13:45), zawierała wystąpienie mgr. Konrada Szymańskiego (UWr) na temat „Fundacja Bazyliki Grobu Świętego w oczach Euzebiusza z Cezarei. Próba reinterpretacji”. Wreszcie sekcja 16 („Dziedzictwo Barbaricum w średniowiecznej Europie i jego mitologizacja w historiografii XIX-XXI wieku"), zaplanowana na piątek (21 IX 2018, godz. 15:15-19:00), objęła również referat dr. Wawrzyńca Kowalskiego (UWr) „Średniowieczne przekazy o przybyciu Słowian na Bałkany i ich interpretacja w historiografii XX wieku".

Jak widać z powyższego zestawienia, tematyce dziejów Bizancjum poświęcono aż 33 referaty. $Z$ tej liczby 14 prelekcji $(42,424 \%)$ przedstawili badacze $\mathrm{z}$ Łodzi $(\mathrm{U} \longleftrightarrow=13$, PolŁ $=1)$, przy czym troje $\mathrm{z}$ nich (dr Z. Brzozowska, prof. dr hab. M.J. Leszka i dr K. Marinow) miało po dwa wystąpienia. $Z$ kolei po 3 referaty $(9,090 \%)$ wygłosili badacze z UAM-u, UG oraz UWr. Osoby reprezentujące Johannes GutenbergUniversität (Moguncja), KUL, Софийски университет „Св. Климент Охридски”, UJ, UJK (Filia w Piotrkowie Trybunalskim), UKSW, UO, UPJPII (Kraków), UP KEN (Kraków) i UZ wystąpili z pojedynczymi prelekcjami. W konsekwencji w tematyce bizantynistycznej niekwestionowany prym wiedli badacze z Uniwersytetu Łódzkiego, co potwierdza tylko fakt, że środowisko to jest dziś w Polsce wiodącym centrum badań nad historią Bizancjum.

Dla kompletności niniejszego sprawozdania warto wspomnieć także o taksach kongresowych. Przewidziano trzy rodzaje opłaty kongresowej: (1) tzw. opłata pełna $(300 \mathrm{zl})$ dla wszystkich pracowników naukowych spoza Wrocławia; (2) opłata ulgowa (220 zł) dla doktorantów niezwiązanych z uczelniami wrocławskimi; (3) tzw. opłata „wrocławska” (123 zł), którą uiszczali pracownicy i doktoranci wrocławskich placówek naukowych. W ramach opłaty pełnej i ulgowej organizatorzy zapewnili uczest- 
nikom kongresu noclegi w dobrych hotelach na wrocławskiej starówce (co na spotkaniach tej rangi zdarza się bardzo rzadko), posiłki w trakcie obrad oraz komplet materiałów konferencyjnych. Opłata „wrocławska” natomiast gwarantowała posiłki w trakcie obrad oraz komplet materiałów konferencyjnych.

Kongres wrocławski cechowała bardzo sprawna organizacja, za co należą się gospodarzom szczere słowa uznania. Należy także podkreślić serdeczność i życzliwość organizatorów na poziomie czysto ludzkim, za co trzeba im również serdecznie podziękować.

Piotr Kochanek, Lublin - KUL

\section{Sprawozdanie z wyjazdu naukowego do Rzymu doktorantów Instytutu Historii Kościoła i Patrologii KUL w dniach 5-11 maja 2019 roku}

W dniach od 5 do 11 maja 2019 roku grupa doktorantów Instytutu Historii Kościoła i Patrologii wraz z opiekunami (ks. prof. Marcinem Wysockim i ks. dr. Marcinem Nabożnym) odbyła podróż naukową do Rzymu w ramach uczczenia 55. rocznicy założenia Instytutu Historii Kościoła na Katolickim Uniwersytecie Lubelskim Jana Pawła II.

Miejscem zakwaterowania był rzymski klasztor Sióstr Nazaretanek przy via Machiavelli 18 będący domem macierzystym tego zgromadzenia. W klasztorze tym znaczną część swego życia spędziła założycielka sióstr - bł. Maria od Pana Jezusa Dobrego Pasterza (Franciszka Siedliska). Po przyjeździe obecni na wyjeździe kapłani odprawili w kaplicy sióstr Mszę Świętą. Po krótkim odpoczynku i kolacji wszyscy udali się do miasta celem zwiedzania okolicznych atrakcji turystycznych.

Następny dzień rozpoczęliśmy Eucharystią w kaplicy klementyńskiej w bazylice św. Piotra. Modlitwa w tak znaczącym miejscu była możliwa dzięki uprzejmości ks. prał. dr. Alberta Warso, absolwenta Instytutu Historii Kościoła i Patrologii KUL, obecnie pracownika watykańskiej Kongregacji Nauki Wiary. Po Mszy udaliśmy się do siedziby kongregacji na spotkanie z jej prefektem - abp. Luisem F.L. Ferrerem SJ. W miłej atmosferze wysłuchaliśmy przemówienia arcybiskupa, po czym przedstawialiśmy tematykę naszych prac doktorskich. Następnie skierowaliśmy kroki do niedostępnej dla zwykłych turystów sali muzealnej, w której zebrano 